\title{
Trajetória histórica do ensino de Design na Universidade do Estado de Minas Gerais-UEMG
}

\author{
Maira Pires Corrêa; \\ Eurico Fernandes Figueiredo Neto; \\ Edson José Carpintero Rezende
}

\section{resumo:}

O presente artigo traz uma trajetóriahistórica a respeito do designna Universidade do Estado de Minas Gerais,apresentando uma investigação sobre a evolução do método de ensino utilizado nos cursos de bacharelado da Escola de Design ao longo dos anos. A reflexão aqui proposta surge como um breve apanhado de rico conteúdo, ainda pouco explorado e carente de documentação. Para tal, tomou-se como referência a consulta de livros, artigos e trabalhos acadêmicos, assim como de depoimentos dos personagens que participaram do percurso da Escola de Design da UEMG. Deste modo, objetivou-se analisar o desenvolvimento da metodologia utilizada pelo corpo docente da instituição na formação dos estudantes. Ademais, buscou-se verificar a importância da união entre conhecimento prático e teórico para elaboração de um diagnóstico sobre o saber acadêmico de design. Contudo, pretendeuse resgatar parte da história, do desenvolvimento e da consolidação do ensino mineiro de design em nível superior.

\section{palavras-chave:}

UEMG; design; linha do tempo; método de ensino; reflexão 


\section{Introdução}

O período entre meados dos séculos XVIII e fins do século XIXcorresponde,a grosso modo, ao surgimento do sistema de fábricas em boa parte da Europa e dos Estados Unidos.A partir de então, percebe-se, de forma mais explícita, o design com o firme propósito de "ordenar" a bagunça do mundo industrial. Houve um grande aumento da oferta de bens de consumo, combinado com a queda concomitante do custo desses bens. Com isso, entraram em campo artistas e arquitetos, reformadores e burocratas, governos, industriais, associações comerciais e profissionais, museus e instituições de ensino, com o intuito de aprimorar o gosto da população e a configuração dos produtos que eram oferecidos(CARDOSO, 2012).

Nesse panorama, a história revela que o ensino de design está relacionado aos acontecimentos da Revolução Industrial europeia, tanto no que se refere às mudanças tecnológicas, como ao que se refere ao processo de acumulação de capital. Cardoso (2004) destaca o pioneirismo das escolas de design alemãs. Em 1919, a Bauhaus ${ }^{1}$ surge na Alemanha como a primeira escola de design, e, posteriormente em 1953, cria-se a escola de $\mathrm{Ulm}^{2}$ (HochschulefürGestaltung - HfG).Observa-se que o ensino formal e institucionalizado do design, de nível superior, somente se deu no século XX com o surgimento da Bauhaus. Durante esse período, alguns artistas, educadores e políticos debatem-se entre ideias utópicas e pragmáticas em torno do sentido e do futuro do design. Com isso, molda-se um modelo de ensino que serviu de base para a formação de escolas de design no Brasil e no restante do mundo (PAULAet al, 2010).

Sendo assim, pode-se dizer que o design, desta maneira compreendido,é um campo do saber relativamente recente se comparado ao estudo de áreas milenares como a arquitetura e a medicina, por exemplo.

Freitas (2017) revela que o registro desta história é atividade ainda mais peculiar enquanto instrumento educativo e de formação cultural para as instituições de ensino e pesquisa. Embora publicações relevantes tenham surgido nos últimos anos, a bibliografia disponível ainda é escassa.Dias, Safar e Avelar (2012) acrescentam a carência de trabalhos que abordem não só as questões referentes à metodologia de ensino e às interfaces com outras áreas do conhecimento, mas também que resgatem ações pioneiras ou a trajetória e o conhecimento adquirido pelas instituições mais antigas.

Em relação aos cursos de graduação em design oferecidos pela Universidade do Estado de Minas Gerais (UEMG), observou-se que há pouco material que resgate a evolução e a consolidação do ensino de design em nível superior, principalmente no que diz respeito à metodologia de ensino utilizada pelo corpo docente que percorreu a instituição ao longo dos anos. Freitas (2017) ressalta o anonimato deste percurso diante do limitado número de livros e artigos que tratam do assunto.

Assim, face a um cenário de lacunas ainda pouco explorado, este artigo objetiva oferecer uma contribuição sobre a trajetória histórica do ensino de design da UEMG em relação ao campus da Escola de Design em Belo Horizonte. Além disso, busca-se estimular outras reflexões, ensaios investigativos e pesquisas mais aprofundadas. Entende-se que quanto mais esse tema for objeto de estudos, professores, alunos, e, por conseguinte, a própria universidade poderão se beneficiar das análises obtidas.

Para construção do presente trabalho, informações foram cruzadas a partir de dados bibliográficos e depoimentos que investigaram a memória dos personagens que fizeram, e, ainda fazem, parte do percurso da Escola de Design da UEMG.No primeirosegmento do texto, aborda-se o ensino de design no Brasilde forma sucinta. Em seguida, estabelece-se uma linha do tempo sobre o surgimento e a evolução do design na UEMG, conforme a criação de cursos específicos. Por último, as considerações finais tecem perspectivas futuras impulsionando a valorização e aprimoramento dos cursos oferecidos em prol do corpo docente, discente, alémde toda a sociedade. Todavia, pretendeu-se

\footnotetext{
${ }^{1}$ Segundo Rafael Cardoso (2004), a Bauhaus era umainstituição estatal que reuniu grande número de pessoascriativasispepe libertárias, umaescola de design que possuiaum modelo pedagógico marcado pela abertura de ideiasinovadoras.

${ }^{2}$ Conforme o mesmo autor, a Escola de Ulm, teveinspiração inicial no legado deixado pela Bauhaus. No entanto, buscava a originalidade e a independência no que tangeao modelo pedagógico de suaantecessora.
} 
contribuir com reflexões acerca do design na universidade mineira,resgatandoa históriado ensino de design na instituição.

\section{0 ensino de design no Brasil}

$\mathrm{O}$ ensino de design no Brasil,iniciou-se em meados do século $\mathrm{XX}$ em sintonia com a política criada por Juscelino Kubitschek e a efervescência cultural gerada pelo amadurecimento das concepções artísticas modernistas (DIAS; SAFAR; AVELAR, 2012).

As primeiras iniciativas do ensino de design em terras brasileiras foram implementadas a partir de 1950 (CARDOSO, 2004; FREITAS, 2017; NIEMEYER, 1997). Entre as décadas de 50 e 70, emergem no Brasil as tentativas precursoras de abertura de cursos voltados às atividades do design nos estados de São Paulo, Rio de Janeiro e Minas Gerais.

Cabe pontuar que,além dos passos paulistas historicamente conhecidosdo Instituto de Arte Contemporânea (IAC) e da Faculdade de Arquitetura e Urbanismo da Universidade de São Paulo (FAU-USP), duas instituições surgem como pioneiras em solo nacional: a Escola Superior de Desenho Industrial (ESDI), considerada a primeira instituição a oferecer um curso de design de nível superior no Brasil, na cidade do Rio de Janeiro, e a Fundação Mineira de Arte (FUMA), atual Escola de Design da Universidade do Estado de Minas Gerais(ED-UEMG) localizada em Belo Horizonte (DIAS; SAFAR; AVELAR, 2012).

Dias, Safar e Avelar (2012), sugerem ainda outras iniciativas de ensino do design no Brasil como, por exemplo, os cursos da Universidade Federal de Pernambuco - UFPE em 1972, da Universidade Federal do Maranhão - UFMA em 1975, da Universidade Federal do Paraná - UFPR em 1974 e da Universidade Federal da Paraíba - UFPB, Campina Grande em1978. Tratam-se de cursos que, distantes uma década ou mais das iniciativas pioneiras em São Paulo, Rio de Janeiro e Minas Gerais, foram os primeiros expoentes em seus contextos regionais.

Atualmente, há um grande número de escolas espalhadas em todo território nacional, contudo cabe aqui destacar apenas algumas das instituições precursoras.

\subsection{São Paulo}

Conforme Niemeyer (1997) e Carvalho (2012), iniciam-se no Museu de Arte de São Paulo (MASP) as primeiras práticas envolvendo o design, sendo inaugurado em 1951 o Instituto de Arte Contemporânea (IAC). Foi uma primeira "experiência" de ensino, tendo durado apenas três anos.

No MASP é que o design passou a ser sistematicamente tratado, seja em suas atividades didáticas e exposições, seja nos seus equipamentos. O IAC do MASP foi uma das primeiras iniciativas no campo do desenho industrial no Brasil, ou seja, foi a semente do ensino do design em nível superior no país (NIEMEYER, 1997; PAULA et al, 2010).

Carvalho (2012), registra que no começo da década de 60, entre as escolas paulistas que possuíam cursos correlatos próximos ao campo do design, encontravam-se os cursos da Universidade Presbiteriana Mackenzie e da Universidade de São Paulo, como ensino superior de arquitetura. Já a Fundação Armando Álvares Penteado (FAAP), contava com importantes artistas nacionais e o incentivo às artes.

No início de 1962, ocorre uma reforma curricular no curso de Arquitetura e Urbanismo da Faculdade de Arquitetura e Urbanismo da Universidade de São Paulo (FAU-USP). Com isso, algumas disciplinas de design são inseridas na grade do curso de arquitetura da instituição (CARVALHO, 2012; PAULA et al, 2010).

Dias, Safar e Avelar (2012), destacam que os primeiros cursos de design em nível superior criados no território paulista foram o curso de Desenho Industrial da Fundação Armando Álvares Penteado (FAAP) em 1968 e os cursos de Desenho Industrial e Comunicação Visual na Universidade Presbiteriana Mackenzie em 1970. Segundo as mesmas autoras, a graduação plena em design na da Universidade de São Paulo (USP) só veio a ocorrer em 2006 como sugestão encaminhada ao governo pela Federação das Indústrias do Estado de São Paulo (FIESP).

Vale registrar, que a falta de pedagogia do início desses cursos é uma característica comum no cenário paulistano e na carioca ESDI, ou seja, os professores de projeto praticavam um ensino 
conforme a prática profissional no mercado. Além disso, havia envolvimento de docentes dos cursos de arquitetura e de artes plásticas com o ensino de design (CARVALHO, 2012).

\subsection{Rio de Janeiro}

A criação da ESDI, em 1962 no então Estado da Guanabara (atual Rio de Janeiro), é tida como um marco histórico. Niemeyer (1997), pontua que a trajetória do ensino do design no Brasil tem suas raízes na Europa, especialmente na Alemanha. A autora traz informações preciosas ao relatar que tanto a Bauhaus quanto a Escola de Ulm foram importantes influências na fundamentação da ESDI em solo carioca.

O curso de design da ESDI foi concebido na virada dos anos 1950-60, a partir do modelo da escola de Ulm, e buscava rever os ideais da Bauhaus sob a perspectiva da sociedade industrial pósguerra. O Brasil passava por um momento de desenvolvimento e otimismo. A ideia de uma Escola de Desenho Industrial local mostrou-se significativa para o governo da Guanabara, que pretendia posicionar o então estado na vanguarda do processo industrial brasileiro.Assim, a escola inicia suas atividades de ensino em 1963, como instituição isolada, pertencente à estrutura da Secretaria de Educação e Cultura da Guanabara (ESDI-UERJ, 2020).

O objetivo principal da instituição, além de firmar-se como modelo de uma educação experimental e livre, foi a criação de um espaço institucional capaz de produzir a identidade nacional dos produtos e dos meios de comunicação visual, legitimando a profissão de designer. Buscou-se, ainda, introduzir o design na pauta do debate público. Como o design era uma área nova do conhecimento, não havia no quadro local docentes capacitados ao seu ensino. Isso resultou na utilização de profissionais formados no exterior, ou mesmo de estrangeiros. Na época, esses docentes fizeram prevalecer a estética formal racionalista da escola de Ulm, o que restringiu o ensaio de novas configurações formais dos produtos desenvolvidos(PAULA et al, 2010).A pouca fundamentação teórica colaborou para que fosse cunhada a máxima: "design que se faz fazendo". Tal assertiva conferia ao exercício profissional em design um caráter vocacional e iniciatório, baseado na própria prática. Além disso, alguns ex-alunos ingressavam na escola como professores logo após a graduação e, em sua maioria, sem aperfeiçoamento acadêmico. Geralmente, eles se dedicavam mais à atividade de profissional liberal do que à docência(NIEMEYER, 1997).

De acordo com Carvalho (2012), a implantação da ESDI é contemporânea às experiências paulistas e alguns dos agentes da instituição carioca, também atuavam na cidade de São Paulo, o que poderia contribuir para supor que determinados princípios que nortearam a formação da academia paulista seriam semelhantes aos da ESDI. Entretanto, não são claros nem confirmados estudos ou pesquisas sobre $\mathrm{o}$ assunto.

O modelo da ESDI consolidou-se como base para outros cursos criados no país. Sua estrutura curricular foi adotada a partir de 1968 e originou a referência para o primeiro currículo mínimo aprovado pelo Conselho Federal de Educação para os cursos de bacharelado em Desenho Industrial. Muitos designers formados pela instituição participaram da criação de diversos cursos de graduação em design no Brasil contribuindo para a disseminação do seu arquétipo (BOMFIM, 1978; COUTO, 2008). Contudo, "a ESDI funcionou como uma escola autônoma até 1975, quando foi incorporada à Universidade do Estado do Rio de Janeiro"(OZANAN, 2005, p. 53). Dada a fusão dos estados do Rio de Janeiro e Guanabara, a ESDI foi integrada pelo decreto ${ }^{\circ} 67$, de 11 de abril de 1975 , à então nascente UERJ (ESDI-UERJ, 2020).

\subsection{Minas Gerais}

Segundo Bahia (2017), o ensino do design em Minas Gerais é uma das experiências precursoras no contexto nacional, mas tema ainda pouco estudado e escasso em publicações. Os registros existentes permitem uma visualização superficial das manifestações de ensino na capital do estado, bem como da metodologia de ensino aplicada e do entendimento do contexto em que os cursos estavam inseridos.

A Escola de Design da Universidade do Estado de Minas Gerais (ED-UEMG)destaca-se nesse cenárioe é o objeto principal de estudo deste trabalho. Apesar da sua trajetória de muitos percalços, a instituição tornou-se uma referência para o ensino do design no país e é conhecida tanto 
nacionalquanto internacionalmente. No que tange à história da Escola de Design da UEMG, é preciso considerar todas as fases que moldaram a instituição ao longo dos anos.

Intimamente ligada ao desenvolvimento do design no país, a ED-UEMG (Escola de Design da Universidade do Estado de Minas Gerais) foi criada em 1955 com o nome de Escola de Artes Plásticas (ESAP), subordinada à já existente Escola de Música da UMA (Universidade Mineira de Arte Fundação Educacional).Em 1954, por sua vez, a UMA foi inaugurada como o resultado da associação com outras instituições: Sociedade Coral, Cultura Artística e Orquestra Sinfônica de Minas Gerais. Já em 1956, a Escola de Artes Plásticas instala um curso preparatório e realiza seu primeiro vestibular, entrando em pleno funcionamento no ano de 1957 (ED-UEMG, 2020).

Em 30 de dezembro de 1963, sob a Lei Estadual 3065 e decreto $n^{\circ} 55068$ de 24 de novembro de 1964, a Universidade Mineira de Arte, juntamente com a Escola de Artes Plásticas (ESAP), foi transformada em Fundação e agregada à Secretaria de Estado do Trabalho e Cultura Popular, passando a denominar-se Fundação Mineira de Arte (FUMA). Em 13 de maio de 1980, sua denominação foi novamente alterada para Fundação Mineira de Arte Aleijadinho, pelo Decreto ${ }^{\circ} 7693$.

Em 1990, a Fundação Mineira de Arte Aleijadinho fez sua opção pela incorporação à recém-criada Universidade do Estado de Minas Gerais. A Universidade do Estado de Minas Gerais (UEMG), em Belo Horizonte, formou-se através da incorporação de tradicionais instituições de ensino, conceituadas em Minas Gerais e no Brasil: o Curso de Pedagogia do Instituto de Educação de Minas Gerais, a Fundação Mineira de Arte Aleijadinho - FUMA e a Escola Guignard. Incorporadas à UEMG, as instituições passaram às seguintes denominações: Faculdade de Educação (FAE-UEMG), Escola de Música (ESMU-UEMG), Escola de Design (ED-UEMG) e Escola Guignard (EDUEMG, 2020).

\section{Trajetória histórica do ensino design na ED-UEMG}

Dias, Safar e Avelar (2012), afirmam que a UMA resultou de um instigante espírito modernizador pelo qual o Estado de Minas Gerais e sua capital Belo Horizonte, passaram nos anos 40 e 50 e, mais especificamente, a Escola de ArtesPlásticas, que deu origem à atual Escola de Design. De uma forma um tanto ingênua, um grupo de jovens idealistas da elite intelectual da época buscou um modelo na escola alemã Bauhaus. Mas,diferentemente de sua antecessora ESDI, eles não mantiveram com esta nenhum contato direto além dos livros e do exercício empírico de seu modelo pedagógico.

Aguiar (2006) relata que,enquanto UMA,a instituição possuía os cursos de Licenciatura em Desenho, Decoração, Desenho Industrial e Desenho de Publicidade os quais foram oferecidos apenas a partir de 1957. Vale dizer que nessa época ainda não se utilizava a palavra design na nomenclatura.

A ESDI e a FUMA foram criadas por meios distintos, mas comungavam o mesmo desejo de construir e institucionalizar o design como profissão e atividade efetivano país (DIAS; SAFAR; AVELAR, 2012).

É importante frisar que alguns autoresdefendem que a carioca ESDI teria sido a escola precursora do ensino de design no Brasilem 1962. Porém, há controvérsias, considerando que a UMA iniciou suas atividades em território mineirono ano de 1957.

Freitas (2017) destaca, segundo o depoimento do ex-aluno Marcelo de Resende, que o curso de Desenho Industrial passou a ser reconhecido como de nível superior de 1965 para 1967. Entretanto, os cursos já eram considerados de nível superior, pelo menos ideologicamente pelos alunos.De acordo com uma pesquisa documental realizada pela autora, este momento parece se tratar, principalmente, de um processo de protocolização, haja vista queo curso de Desenho Industrial já assumia certa postura como sendo de nível superior desde o seu primeiro percurso de formação, iniciado em 1960.

Ainda conforme Freitas (2017), pouco se sabe sobre os primeiros egressos do curso de Desenho Industrial da escola.Mas,quase todos os nomes dos alunos que concluíram o curso de Desenho Industrial nesta época, foram encontrados no livro de Ata de Colação de Grau. Entre eles, está o primeiro formando: Eduardo Lopes da Silva, graduado em janeiro de 1963. 
Contudo, os princípios gerais que nortearam todo o trabalho idealizado em Minas para o Design estavam baseados em três características da Bauhaus: o paralelismo entre o ensino teórico e prático, o contato permanente com a realidade do trabalho e a presença deprofessores criativos. Não havia um projeto pedagógico claro, os currículos foram desenvolvidos como resultado de pesquisas nos livros da escola alemã e em revistas especializadas na produção de designers de toda parte do mundo. Ademais, existia uma influência pessoal de cada professor responsável pelo direcionamento das atividades didáticas. Com isso, os cursos procuraram adaptar-se à necessidade da época sem uma "metodologia" definida (AGUIAR, 2006).

Freitas (2017) afirma que no primeiro ano do percurso acadêmico em Design as disciplinas eram comuns a todos os cursos. As turmas eram mistas, com a participação de alunos de Desenho Industrial, Decoração, Licenciatura em Desenho e Desenho de Publicidade. Apenas a partir do segundo ano, eram inseridas disciplinas mais específicas e, neste formato, o aluno direcionava seu curso seguindo até sua conclusão. Aguiar (2006), por meio do relato do ex-aluno e ex-professor Osvaldo Coutinho do Amaral, ingresso em 1967, destaca que a escola nessa época era reduzida e tinha apenas 100 estudantes. Como as grades eram coletivas, os alunos de todos os cursos conviviam nas mesmas salas. O interesse pela profissão era pequeno e muitos desistiam antes de finalizar os estudos.

Ainda na década de 60, foi criado o IPPI (Instituto de Pesquisa e Projetos Industriais) pelo idealismo de estudantes e professores. "A iniciativa registra o amadurecimento das relações entre mestres e alunos, uma das características que marcaram o ensino do design em Minas" (AGUIAR, 2006, p. 56). Seus mentores, os ex-alunos Marcelo de Resende e Eduardo Lopes - sendo este último já professor - concretizavam um ideal de fazer valer a teoria na prática. Os trabalhos eram inovadores e se baseavam num caráter experimental, desenvolvido por meio de pesquisas, testes e prototipagem. Porém, ambos se desligaram da universidade e o instituto teve seu fim. Conforme depoimento de Radamés Teixeira da Silva ${ }^{3}$, arquiteto-urbanista e ex-professor, o IPPI contribuiu para um definitivo entrosamento entre a UMA e os meios empresariais, prestando serviço de grande valor às indústrias mineiras(AGUIAR, 2006).

Atividades artesanais também eram abraçadas na escola. Em 1965, Aguiar (2006), registra, em declaração de Eduardo Lopes, que um aluno muito pobre teve uma sala cedida pela direção para que pudesse fazer calçados artesanais, o que foi um sucesso e lançou moda em BH na ocasião.

Outro ponto importante a ser destacado é que os cursos de design só foram reconhecidos pelo Ministério da Educação e Cultura (MEC) em 1968 como resultado da Reforma Universitária n 5.540 (BAHIA, 2017; CARVALHO, 2012).

Apesar da grande expansão industrial, o design não era muito considerado em Minas. Enquanto os profissionais abriam o mercado, a escola evidenciava a crise no Estado. A FUMA realizava um trabalho solitário na década de 70 . Com recursos escassos, baixa anuidade e poucos alunos matriculados, a instituição "sobrevivia de subvenções eventuais, auxílios federais e estaduais incertos. Não raro, os professores ficavam meses sem receber salários” (AGUIAR, 2006, p. 79).

A sede do Barro Preto, que funcionou na Av. Augusto de Lima por 20 anos, foi demolida de forma intempestiva em 1973 para dar lugar à uma construção de umórgão da justiça. Aguiar (2006) registra que a mudança ocorreu após muita luta para se encontrar um prédio temporário, o Grupo Escolar Juscelino Kubitschek, localizado no Viaduto São Francisco. Em 1976, acontece uma nova transferência de endereço para a Av. Amazonas, no bairro Gameleira. Foram tempos difíceis, marcados por infraestruturas precárias, frustrações da comunidade acadêmica e pouco apoio político das autoridades da época. No ano letivo de 1977, a escola passou a funcionar em três turnos visando o melhor aproveitando das poucas salas disponíveis (OZANAN, 2005).

Dijon de Moraes, ex-aluno e posteriormente professor, relata que a década de 1980 inicia-se com esperanças alimentadas pela expansão das atividades e pela mudança para uma sede definitiva a ser construída num terreno no bairro Santa Lúcia (AGUIAR, 2006). Infelizmente, o plano de construção no local nunca foi efetivado.

Em sequência, o imóvel da Gameleira foi se adequando às necessidades de ensino. "O conjunto de edifícios não comportava de forma adequada as atividades da escola, especialmente pela

\footnotetext{
${ }^{3}$ Silva, Radamés Teixeira. O Parto da Montanha, Módulo 12-13, Revista Trimestral de Diseño Industrial Setiembre-Diciembre 1983. Especial Brasil - p. 33. Trilingue. Apartado 159, Cartago, Costa Rica, dez. 1983.
} 
expansão da oferta de Pesquisa e de Extensão" (AGUIAR, 2006, p. 131). Assim, após uma negociação de permuta, o terreno foi ampliado o que permitiu futuras intervenções.

Em 1989, com a promulgação da Constituição do Estado de Minas Gerais, foi criada a Universidade do Estado de Minas Gerais - UEMG (OZANAN, 2005). A FUMA foi absorvida pela UEMG nos anos 90, inaugurando uma nova fase institucional, administrativa e pedagógica.

A partir de então, a escola de design começa a estruturar suas atividades de pesquisa e extensão, surgindo o LDG (Laboratório de Design Gráfico), o Centro de Extensão e o CPqD (Centro de Pesquisa em Design e Ergonomia) respectivamente(MOL, 2017).

O LDG foi criado para atender as demandas de design gráfico da universidade como um todo, ficando responsável pela conceituação e criação de identidades visuais, materiais institucionais, peças gráficas de divulgação do vestibular, seminários, workshops e outros eventos (MOL, 2017).

O Centro de Extensão surgiucom três finalidades: desenvolver cursos de curta duração, projetos de design e exposições com a produção da universidade. "O Centro passou a interagir com acomunidade como um todo, seja em consultoria, assistência técnica ou na elaboração de projetos" (AGUIAR, 2006, p. 130).

OCPqD foi inaugurado em 1993 pelo ex-aluno e professor Jairo José Drummond Câmara. Este setor proporcionou aos docentes a oportunidade de realizar pesquisas mais aprofundadas em design e aos estudantes o acesso à iniciação científica. Desde então o Conselho Nacional de Desenvolvimento Científico e Tecnológico (CNPq) e a Fundação de Amparo à Pesquisa do Estado de Minas Gerais (FAPEMIG) concederam bolsas de estudos para professores e alunos (AGUIAR, 2006).

Nesse contexto, parte significativa da configuração atual da Escola de Design se deve ao trabalho e dedicação do ex-aluno e ex-professor Romeu Dâmaso. Moreira (2017), aponta que a partir de 1997, o professor orientava os alunos da disciplina "Prática Projetual" a visitarem micro e pequenas empresas, dando-lhes a oportunidade de conhecer in loco a realidade tecnológica e as dificuldades dos empresários locais. Tal iniciativa foi de grande importância, pois revelou o potencial da escola e contribuiu para aguçar o interesse dos alunos durante as atividades. Em 2003, foi iniciativa de Romeu a criação do Centro de Integração Design Empresa (Centro IDE) que pretendia promover mecanismos de inserção do Design em diferentes setores. A ação teve grande receptividade e coincidiu com a implantação do novo projeto pedagógico da Escola de Design.

Frente ao século XXI, contando com cerca de 1.400 vagas disponíveis, a Escola de Design continuava reafirmando a qualificação profissional de seus mestres e alunos recebendo títulos e premiações. Porém, a condição da infraestrutura mostrava-se cada vez mais deficiente, o queocasionou mais uma mudança provisória da sede. Em 2003, o primeiro semestre letivo iniciou-se num prédio alugado no bairro Lagoinha que foi apelidado de "Carandiru" devido às péssimas instalações. Após reformas emergenciais, as aulas voltaram a ser ministradas na edificação da Gameleira. Pouco tempo depois do retorno surgiu a notícia de expansão do Expominas ${ }^{4}$ e consequente desalojamento do campus de design. Mais uma vez emerge a promessa de construção da sonhada sede em um terreno localizado na Av. José Cândido da Silveira (AGUIAR, 2006).

No ano de 2004, além das alterações curriculares, observou-se forte impulso nos laboratórios e nas atividades dos núcleos de pesquisa/extensão. A constante busca por novos conhecimentos e inovação deu ânimo ao trabalho realizado em diversos setores como o Centro de Estudos em Design da Imagem, o Centro de Estudos em Design da Madeira, o Centro de Estudos Teoria, Cultura e Pesquisa em Design, entre outros.

Entretanto, mesmo diante de notável crescimento, a escola ainda permanecia sem o respaldo merecido. Em 2006, o descaso com a instituição culminou em nova mudança da sede para a Avenida Antônio Carlos, na Pampulha. Abandonados os planos de construção na Av. José Cândido da Silveira, os problemas estruturais persistiam na esperança de conquista da unidade definitiva.

Em 2011, por iniciativa do Governo do Estado, foram iniciados os trâmites para que a Escola de Design se transferisse para o antigo prédio do IPSEMG (Instituto de Previdência dos Servidores do Estado de Minas Gerais) na Praça da Liberdade, ponto nobre de Belo Horizonte. As obras de reforma do edifício foram iniciadas em 2014, mas em virtude de questões técnicas e patrimoniais que

\footnotetext{
${ }^{4}$ É um centrode eventos localizado na cidade de Belo Horizonte que possui infraestrutura para realização de feiras, exposições, congressos, eventos corporativos, culturais e sociais.
} 
determinaram paralizações temporárias, os trabalhos só foram concluídos no ano corrente de 2020 (ED-UEMG, 2020).

Atualmente, a Escola de Design passa por mais um período de instabilidade diante da pandemia da Covid-19. O primeiro semestre letivo se reiniciariano prédioreformado para receber a escola, mas, devido ao risco de contágio, as aulas estão sendo ministradas provisoriamentede maneira remota em sistema totalmente online. Entretanto,a comunidade acadêmica aguarda esperançosa por orientações das autoridades sanitárias visando a liberação ea retomada das aulas presenciais, para enfim inaugurar-se a nova sede.Todavia, espera-se que a instituição possa enfim fixar raízes na atual promessa de realocação para o novo e tão sonhado campus da Praça da Liberdade.

AEscola de Design é hoje, uma das unidades da Universidade do Estado de Minas Gerais que, além das atividades de ensino, desenvolve atividades de pesquisa e extensão. Os cursos de Decoração, Desenho Industrial, Desenho de Publicidade e Licenciatura constituíram a base dos cursos atualmente oferecidos na graduação - Design de Ambientes, Design de Produto, Design Gráfico e Licenciatura em Artes Visuais respectivamente (DIAS; SAFAR; AVELAR, 2012). Nota-se, ainda, a inclusão posterior dobacharelado em Design de Moda. Além disso, são oferecidos cursos de Pós-Graduação latu sensu- Design de Gemas e Joias, Design de Móveis, Design de Calçados e Bolsas e Gestão do Design em Micro e Pequenas Empresas - e Pós-Graduação stricto sensu- Mestrado e Doutorado em Design.

AED-UEMGtambém desenvolve projetos culturais, busca parcerias com outras instituições e empresas, vislumbrando novos caminhos para aprendizagem contínua e aperfeiçoamento profissional. A escola tem exercido forte influência no design mineiro ao explorar profundamente as relações design/sociedade. Seus alunos ocupam posições de destaque no cenário nacional, trabalham e prestam serviços para organizações renomadas e, frequentemente, vencem concursos nacionais e internacionais dentro dos vários setores do design.Alicerçada em sua bem-sucedida experiência e na crescente capacitação do seu corpo docente, a escola vem desenvolvendo um ensino de design que, dinamicamente, dialoga com as permanentes movimentações e exigências do mundo contemporâneo (ED-UEMG, 2020).

Ademais, o design, com toda sua potencialidade, tem englobado cada vez mais atividades do âmbito social, humanístico, tecnológico e artístico, ganhando força e destaque no mercado (AGUIAR, 2006).

Desta forma, apresenta-se em sequência, despretensioso apanhado sobre a história do ensino implementado pela instituição mineira desde os seus primórdios em seus cursos específicos. Nota-se, que grande parte do material encontrado refere-se aos cursos de Desenho Industrial e Decoração, sendo intitulados nos dias atuais como Design de Produto e Design de Ambientes respectivamente. Em relação a esses cursos, observa-se que os mesmos se aproximam das áreas de engenharia e arquitetura, tendo em conta que tais setores serviram como "pano de fundo" no desenvolvimento dos cursos. Nola e Corrêa (2020) pontuam, que o design, especialmente na esfera de ambientes, está interligado à arquitetura e à engenharia, sendo importante a parceria entre essas áreas. Contudo, registra-se que o curso de Desenho de Publicidade, agora denominado por Design Gráfico, foi aqui bem pouco explorado devido à carência de material encontrado como referência de pesquisa.

\subsection{O curso de Desenho Industrial / Design de Produto}

Logo que foram iniciadas as atividades de ensino do curso de Desenho Industrial da UMA, percebeuse que as peculiaridades e as limitações econômicas e tecnológicas da época direcionariam o curso para a construção de seus próprios preceitos didáticos (FREITAS, 2017).

O primeiro currículo privilegiava as disciplinas técnicas e demonstrava uma aproximação com as disciplinas da arquitetura. Segundo Ozanan (2005), o curso de Desenho Industrial foi idealizado por um grupo de arquitetos e urbanistas preocupados em inserir Minas Gerais no contexto industrial. Freitas (2017) reforça este aspecto ao afirmar que desde o início do curso um aspecto pedagógico e estratégico que se destacou foi a preocupação em trabalhar a aproximação do aluno como mercado de atuação de forma simultânea à sua formação acadêmica. A proposta pedagógica para o período de 1960 a 1970 foi conduzida pela tricotomia arte, técnica e tecnologia. Este aspecto pode ser exemplificado pelo corpo docente da escola que era formado por artistas veteranos da instituição, egressos dos cursos de Licenciatura em Desenho e por arquitetos que conferiam o caráter do curso. 
Estes últimos eram na sua maioria, docentes e ex-alunos da Escola de Arquitetura da Universidade Federal de Minas Gerais (UFMG).

As disciplinas que envolviam a execução construtiva eram caracterizadas como aquelas que geram conhecimento pela prática. Naquela época, a oficina de marcenaria era local de discussões, "experimentos projetuais e de elucubrações profissionais, entre alunos e professores" (FREITAS, 2017 , p. 25). Tal fato reforça que o currículo do curso de Desenho Industrial estava calcado em referências teóricas e no empirismo, sendo neste último o seu diferencial. Importante ressaltar que o carente acervo bibliográfico da escola era compensado pelo esforço dos professores que compartilhavam sua própria bibliografia com os alunos (FREITAS, 2017).

Em 1966, o curso de Desenho Industrial tinha carga horária de 1.770 horas e podia ser concluído após três anos (OZANAN, 2005). A proposta didática considerava o modelo da Bauhaus, da Escola de Ulm e da Escola deChicago, sendo que o contexto projetual adotado durante o curso levava em conta a realidade produtiva somada a tecnologia local e nacional (FREITAS, 2017). Destaca-se que em 1968, o currículo do curso foi reconhecido pelo MEC como de nível superior.

Nessa época, a disciplina "Desenho de Móveis" não apresentava conteúdoespecífico sendo tratada como uma extensão da disciplina "Desenho Industrial", que em 1970 passou a ser denominada como "Planejamento, Projeto e Desenvolvimento", atual "PráticaProjetual." Segundo Freitas (2017), a disciplina "Desenho Industrial" absorvia cerca de 50\% da carga horária total do período em que era lecionada.

Para as demais disciplinas, as aulas eram de temas livres e/ou de desenvolvimento de habilidades cognitivas e técnicas em conhecimentos específicos, como por exemplo, as disciplinas Técnicas de ComposiçãoArtística, Modelagem e Escultura, Perspectiva e Sombras ou Geometria descritiva. A maioria das disciplinas se repetia no decorrer do curso, e seus conteúdosevoluíam de complexidade de acordo com o andamento do curso (FREITAS, 2017, p. 40).

A partir de 1970 o curso passa de três para quatro anos de formação. Ozanan (2005) aponta que o novo currículo era mais próximo do curso de Licenciatura em Desenho e Plástica. Para Freitas (2017), o novo currículo não alterou o perfil do curso, visto que o caráter artístico continuava a prevalecer no número de disciplinas, mas não no conteúdo abordado. As disciplinas acrescidas foram desdobramentos das já existentes e constituíam uma formalização para atender às exigências do currículo mínimo estabelecido pelo Ministério da Educação em 1969.

Em 1988, a Matriz Curricular passa para 3.975 horas, e o aluno deveria estar matriculado por no mínimo 5 anos para a conclusão do curso. Conforme Ozanan (2005), o curso aproximava-se muito da Engenharia e tinha como meta aplicar os conhecimentos científicos à invenção, aperfeiçoamento ou utilização da técnica industrial em todas as suas determinações.

Ozanan (2005) analisa a mudança curricular com base nas responsabilidades conferidas a cada departamento em relação ao total do curso de Desenho Industrial: o Departamento de Tecnologia e Ciência (DETC) ficou responsável por $40 \%$ das disciplinas, o Departamento de Arte e Cultura (DEAC) por 19,72\%, o Departamento de Planejamento e Projeto (DEPP) por 32,83\% e a Educação Física por $6 \%$.

O currículo implantado na Escola de Design em 1989 permaneceu até 2003, quando uma nova proposta foi entregue ao colegiado do curso de design. Esta proposta foi resultado de vários anos de trabalho e envolveu vários professores da escola. Sua estrutura é dividida em 3 grupos principais: núcleo básico comum (disciplinas obrigatórias fixas), habilitação (disciplinas obrigatórias variáveis) e ênfase (disciplinas optativas). A análise de Ozanan (2005) diz que este currículo procurou distribuir as disciplinas de forma equilibrada: $28,7 \%$ de disciplinas teóricas, $35 \%$ de disciplinas práticas e $36,3 \%$ ficaram com disciplinas teórico-práticas.

$\mathrm{Na}$ visão dos idealizadores, o novo currículo segue orientações que conferem maior flexibilidade de conteúdos aos professores na medida em que surgem temas diferenciados. Por ser um currículo aberto a propostas, ele cria possibilidades de desenvolvimento das expertises da escola ou mesmo o atendimento à vocação da indústria local e do setor produtivo (OZANAN, 2005). 


\subsection{O curso de Decoração / Design de Ambientes}

No período de 1968 até 1976 o curso de Decoração se manteve idêntico em sua estrutura formal. Possuía entrada anual e uma organização de 29 disciplinas que totalizavam 3.060 horas/aula. No ano de 1982, ocorreu uma mudança significativa e o curso passou a ser dividido semestralmente. A disciplina "Matemática Aplicada" deixou de existir e a ênfase destinada ao desenho técnico se desdobrou em desenho artístico e desenho arquitetônico. Também surgiram as disciplinas de "Fundamentos da Comunicação", "Estética", "Materiais Expressivos" e "Fotografia" (BAHIA, 2017). "As primeiras grades, bem como a ementa das disciplinas ofertadas, eram ora pautadas na arte, propondo uma liberdade formal e estética, ora pautadas na arquitetura, defendendo primordialmente a técnica" (BAHIA, 2017, p. 54).

Entre o final da década de 80 e início do ano 2000, o curso de Decoração passou por mudanças organizacionais que desencadearam a inserção de estudos sobre a conexão do homem com o espaço e a psicologia social. Bahia (2017) traz o relato de Samantha Cidaley de Oliveira Moreira, ex-aluna ingressa em 1989 e também ex-professora. Ela conta que o curso de Decoração era carente de fundamentação teórica e os professores impunham estilos por não terem métodos. Em decorrência disso, a disciplina "Ergonomia" substituiu "Anatomia Artística" na estrutura curricular colocada em prática no $1^{\circ}$ semestre de 2001 .

Já em 2004, é sugerida uma nova revisão na grade que teve como três principais pilares: a alteração do nome de Decoração para Design de Ambientes, a inserção da disciplina de "Metodologia Aplicada ao Projeto de Design" e a unificação das disciplinas de projeto em uma só, a "Prática Projetual"'(BAHIA, 2017). Nesse momento, o Conselho Nacional de Educação - Câmara de Educação Superior, através da Resolução $\mathrm{n}^{0} 5$, de 8 de março de 2004, aprova as Diretrizes Curriculares Nacionais do Curso de Graduação em Design (ABREU, 2015; BAHIA, 2017).

É válido registrar que o nome 'Decoração' era de certo modo pejorativo e estigmatizado, podendo ser este um dos fatores que motivaram a mudança ocorrida.Observa-se, entretanto, que a real alteração ocorreu quando o pensamento do Design foi inserido nas disciplinas e internalizado por docentes/discentes(ABREU, 2015; BAHIA, 2017; NOLA; CORRÊA, 2020). Assim, diante da necessidade de constante aprimoramento, entende-se "que a proposta da reestruturação do curso de Decoração para Design de Ambientes consistiu em uma mudança positiva de pensamento compreendendo os fundamentos do Design" (BAHIA, 2017, p. 65).

Contudo, apenas no ano de 2008 a disciplina de Metodologia ganhou uma nova ementa e a utilização do método ensinado foi exigido nas Práticas Projetuais. Para Ana Célia Carneiro Oliveira, ex-aluna e professora, "a metodologia de projeto se tornou uma prática aplicada ao ensino quando o curso de Design de Ambientes incluiu professores de outras especialidades do Design em seu corpo docente" (BAHIA, 2017, p. 63).

\subsection{O curso de Desenho de Publicidade / Design Gráfico}

O curso de Design Gráfico da UEMG, antigamente denominado Desenho de Publicidade, tem como grande destaque o LDG (Laboratório de Design Gráfico).De acordo com Iara Mol (2017), o núcleo nasce nos anos 90, por iniciativa da professora Maria Bernadete dos Santos Teixeira, que pretendia criar um espaço para "divulgar mais o design gráfico" e experimentar a prática projetual de forma complementar à da sala de aula.

No início, o laboratório ficava em uma pequena sala onde cabiam apenas duas pranchetas e dois estagiários e atendiaapenas demandas internas. Posteriormente, foi crescendo, ampliando sua capacidade de atendimento e outras salas tiveram de ser anexadas ao espaço(MOL, 2017).

Com relação ao desenvolvimento metodológico e da prática projetual, observa-se que o aluno - que tinha a oportunidade de estagiar no Laboratório - estava em outro patamar. Isso se devia ao fato dele perseguir sempre novas formas de representar e buscar soluções diferentes. Em sala de aula, o aluno estagiário normalmente se destacava por levar naturalmente essa prática para as atividades de classe. A relação Laboratório e sala de aula era sempre muito proveitosa (MOL, 2017, p.102). 
Desde sua criação,o LDG objetiva serum espaço destinado ao aprendizado da atividade projetiva.É formado por professores orientadores e alunos estagiários, além de colaboradores internos e externos que desenvolvem projetos e pesquisas de novas técnicas e materiais. "Em todos esses anos, os participantes puderam experimentar, reinventar métodos e linguagens e colaboraram de forma interdisciplinar no desenvolvimento de projetos de design" (MOL, 2017, p.97). Desta forma, ressaltase, a relevante contribuição que este centro teve e tem para o ensino da prática projetual, especialmente no âmbito do Design Gráfico da Escola de Design da UEMG (MOL, 2017).

Destaca-seque em função do escasso referencial teórico encontrado,principalmente no que tange ao ensino do curso de Design Gráfico e à prática docente, é possível afirmar que novas pesquisas sobre a história da instituição permitirão discussões sob um ponto de vista mais amplo e melhor fundamentado.

\section{Considerações finais}

Apesar do exponencial crescimento no mercado acadêmico eprofissional, falar sobre design, em qualquer de seus segmentos, é uma tarefa desafiadora, haja vista que se trata de uma profissão relativamente recente em todo o globo.

A revisão narrativa da literatura mostrou que a Escola de Design da UEMG é um modelo de referência em design no Brasil apesar de sua trajetória carregada de percalços. Sua metodologia de ensino adaptou-se às circunstâncias e superou adversidades no decorrer do tempo.

A grande carência de informações detalhadas referentes ao ensino experienciado ao longo dos anos destaca a importância de expansão de estudos como este. Observa-se que a maior parte das informações procede da coleta de depoimentos e de buscas bibliográficas publicadas recentemente de forma ainda muito resumida. Entretanto, pode-se afirmar que as deficiências iniciais observadas pela ausência de um projeto pedagógico claro e pela falta de formação pedagógica específica em design dos educadores foram vencidas. Os currículos passaram por revisões necessárias para a dilatação do conhecimento conforme a evolução da sociedade.

Além disso, a instituição foi construindo um quadro bem preparado de mestres, doutores e pósdoutores que atuam tanto no ensino quanto nas atividades de pesquisa. A ED-UEMG permanece formando profissionais em design com excelência. Alunos e professores se destacam continuamente no mercado de trabalho, tanto em nível nacional quanto internacional.

Diante dos relatos expostos, verificou-se também que vários ex-alunos se tornaram professores da instituição. E, que grande parte das publicações a respeito da história e do método de ensino provém, inclusive, da equipe docente e discenteda própria escola.

Vale dizer, ainda, quea implantação do Programa de Pós-graduação disponibilizou os cursos de mestrado e doutorado, o que permitiu a ampliação de novos horizontes no desenvolvimento do ensino e da pesquisa.

Pode-se afirmar, contudo, que a valorização do aprendizado pela união entre conhecimento teórico e prático é a ferramenta base na formação de profissionais. É primordial que haja uma revisão permanente do ensino do design, com renovações curriculares na busca de disciplinas que proporcionem o desenvolvimento da capacidade crítico-reflexiva embasada em aspectos sociais, culturais, econômicos e tecnológicos.

Ademais, a transitoriedade em diversos endereços e a precariedade de infraestrutura não se apresentaram como barreiras intransponíveis para todos aqueles que almejam verdadeiramente o conhecimento.Próxima da mudança definitiva para a sede própria, a Escola de Design da UEMG vence dia após dia as inúmeras dificuldades vivenciadas desde sua fundação. Além disso, os cursos de design encontram-se em constante expansão e espera-se que os próximos egressos possam usufruir de bom espaço físico e recursos institucionais que permitam ainda mais melhorias no método e práticas de ensino.

Por fim, estima-se uma próspera evolução do ensino de design, principalmente no que diz respeito ao amadurecimento das bases teóricas e metodológicas.Não pretende-se esgotar a temática investigada, pois as proposições aqui apresentadas devem ampliar o debate e a reflexão. Assim sendo, torna-se relevante o desenvolvimento de estudos futuros para análise mais detalhada da trajetória do design na Escola de Design da UEMG. 
Historical trajectory of design teaching at the StateUniversity of Minas Gerais UEMG

Abstract: This article presents a historical trajectory about design at the State University of Minas Gerais, bringing an investigation about the teaching method used in the bachelor's degree courses in School of Design. The reflection proposed here appears as a brief survey of rich material, still little explored and lacking in documentation. For that, reference was made of books, articles and academic works, as well as testimonies of the characters who participated in the history of the UEMG's Design School. In this way, the objective is to analyze the development of the methodology used by the teaching staff of the institution in the graduation of students. In addition, it seeks to verify the importance of the union between practical and theoretical knowledge, elaborating a diagnosis about the academic knowledge of design. However, it intends to recover part of the history about the development and consolidation of the Minas Gerais design education.

Keywords: UEMG; design; timeline; teaching method; reflection

\section{Referências bibliográficas}

ABREU, Simone Maria Brandão Marques de. Aspectos subjetivos relacionados ao design de ambientes: isêpium desafio no processo projetual. 2015. 159f. Dissertação (Mestrado em Design) Universidade do Estado de Minas Gerais, UEMG. Belo Horizonte, 2015.

AGUIAR, Dorinha. O Design em Minas - 50 anos. Edição Especial. Belo Horizonte, 2006.

BAHIA, Isabella Pontello. Da Decoração ao Design șẹp de Ambientes: mudanças e permanências, um estudo sobre a experiência na Escola de Design da UEMG. BRAGA, Marcos da Costa; ALMEIDA, Marcelina das Graças; DIAS, Maria Regina Álvares Correia (Org.). In: Histórias do design em Minas Gerais. Belo Horizonte: EdUEMG, 2017. p. 49-67.

BOMFIM, Gustavo Amarante. Desenho Industrial: uma proposta para reformulação do currículo mínimo, 1978. 133f. Dissertação (Mestrado em Engenharia) - Universidade Federal do Rio de Janeiro/COPPE/UFRJ-Rio de Janeiro, 1978.

CARDOSO, Rafael. Uma introdução à história do design. São Paulo: Blucher, 2004.

CARDOSO, Rafael. Design para um mundo complexo. São Paulo: Cosac \&Naif, 2012.

CARVALHO, Ana Paula Coelho de. 0 ensino paulistano de design: a formação das escolas pioneiras, 2012. 300f. Dissertação (Mestrado em Design e Arquitetura) - Faculdade de Arquitetura e Urbanismo da Universidade de São Paulo / FAUUSP, 2012.

COUTO, Rita Maria de Souza. Escritos sobre ensino de design no Brasil. Rio de Janeiro: Rio Book's, 2008.

DIAS, M. Regina Álvares; SAFAR, Giselle Hissa; AVELAR, JohelmaPires; "The historical trajectory of the pioneers of design education in Brazil: ESDI/ UERJ and ED/UEMG", p. 83-87. In: Farias, Priscila

Lena; Calvera, Anna; Braga, Marcos da Costa \& Schincariol, Zuleica (Eds.). Design frontiers: territories, concepts, technologies [ICDHS 2012 - 8th Conference of the International Committee for Design History \& Design Studies]. São Paulo: Blucher, 2012. São Paulo: Blucher, 2014.

ED-UEMG, Escola de Design - Universidade do Estado de Minas Gerais. História. Disponível em: <http://ed.uemg.br/sobre-a-ed/historia/>. Acesso em 13 set. 2020.

ESDI-UERJ, Escola Superior de Desenho Industrial - Universidade do Estado do Rio de Janeiro.

História: a Esdi. Disponível em: <http://www.esdi.uerj.br/a-esdi/historia>. Acesso em 13 set. 2020. 
FREITAS, Ana Luiza Cerqueira. O curso de desenho industrial da FUMA: da criação aos primeiros egressos. BRAGA, Marcos da Costa; ALMEIDA, Marcelina das Graças; DIAS, Maria Regina Álvares Correia (Org.). In: Histórias do design em Minas Gerais. Belo Horizonte: EdUEMG, 2017. p.17-48.

MOL, Iara Aguiar. Panorama histórico do Laboratório de Design Gráfico da Escola de Design da UEMG. BRAGA, Marcos da Costa; ALMEIDA, Marcelina das Graças; DIAS, Maria Regina Álvares Correia (Org.). In: Histórias do design em Minas Gerais. Belo Horizonte: EdUEMG, 2017. p.95-114.

MOREIRA, Samantha Cidaley de Oliveira. História de vida docente: contribuições do professor Romeu Dâmaso para a construção da Escola de Design da UEMG. BRAGA, Marcos da Costa; ALMEIDA, Marcelina das Graças; DIAS, Maria Regina Álvares Correia (Org.). In: Histórias do design em Minas Gerais. Belo Horizonte: EdUEMG, 2017. p. 69-94.

NIEMEYER, Lucy. Design no Brasil: origens e instalação. Rio de Janeiro: 2AB, 1997.

NOLA, Luiz Henrique de Sena; CORRÊA, Maira Pires. Cap. IX. Pag. 127-136. Ética profissional e design de ambientes. Ética profissional e design de ambientes. In: REZENDE, Edson José Carpintero (org).

Design de ambientes em pauta. Curitiba: Editora CRV, 2020.

OZANAN, Luiz Henrique. 0 curso de design em Minas Gerais: da FUMA a Escola de Design, 2005. 118f. Dissertação (Mestrado em Educação) - Universidade Vale do Rio Verde de Três Corações / Unicor-Campus Betim, 2005.

PAULA, Adma Jussara Fonseca de et al. Breve história e análise crítica do ensino do design no Brasil. Convergências: Revista de Investigação e Ensino das Artes. Portugal: Escola Superior de Artes Aplicadas / Instituto Politécnico Castelo Branco, v.III, n.5, 2010. 